\title{
Coping with perceived ethnic prejudice on the gay scene
}

\author{
Rusi Jaspal \\ De Montfort University, Leicester, UK \\ Åbo Akademi University, Turku, Finland
}

\begin{abstract}
There has been only cursory research into the sociological and psychological aspects of ethnic/racial discrimination among ethnic minority gay and bisexual men, and none that focuses specifically upon British ethnic minority gay men. This article focuses upon perceptions of intergroup relations on the "gay scene" among young British South Asian gay men (BSAGM) and the impacts of perceived prejudice for their identities. Twelve young BSAGM were interviewed about their experiences. The qualitative data were analyzed using thematic analysis, which yielded the following themes: (1) Ethnic otherization on the gay scene, (2) Mechanisms of rejection on the gay scene, and (3) Nowhere to turn: double rejection and identity threat. The data indicate that young BAGM may face multiple layers of rejection - racism and homophobia from the general population, homophobia from the ethno-religious community and racism from White British gay men. This can deprive young BSAGM of the only remaining source of social support that they perceive - namely the sexual ingroup - inducing negative social and psychological outcomes for identity processes.
\end{abstract}

\section{Keywords}

racism; discrimination; exclusion; identity; gay youth; British South Asians

\section{Correspondence}

Professor Rusi Jaspal, Faculty of Health and Life Sciences, De Montfort University, Leicester LE1-9BH, United Kingdom. Tel: 0116257 7109. E-mail:

rusi.jaspal@cantab.net

\section{Citing this article}

Jaspal, R. (in press). Coping with ethnic prejudice on the gay scene. Journal of LGBT Youth.

\section{Author biography}

Rusi Jaspal is Professor of Psychology and Sexual Health and Deputy Director of the Mary Seacole Research Centre at De Montfort University, Leicester, UK. He is also Visiting Professor at Åbo Akademi University, Turku, Finland. His current research focuses upon identity processes and identity threat, particularly among ethnic, religious and sexual minorities. Professor Jaspal's research has been published in journals such as British Journal of Social Psychology, Culture, Health and Sexuality and Journal of Homosexuality. Rusi Jaspal is associate editor of the Journal of Social and Political Psychology and co-editor (with Dame Glynis Breakwell) of Identity Process Theory: Identity, Social Action and Social Change (Cambridge University Press, 2014). 


\title{
Coping with perceived ethnic prejudice on the gay scene
}

\author{
Rusi Jaspal \\ De Montfort University Leicester, UK \\ Åbo Akademi University, Turku, Finland
}

In the West, the social and legal positions of lesbian, gay and bisexual (LGB) individuals have gradually undergone significant improvements, although homophobia does continue to affect LGBT people's lives (Trappolin et al., 2012). Ethno-religious minority LGB individuals may experience a double-sided homophobia, that is, from both the general population and their ethno-religious communities (Yip, 2012). Recent research into the identities and experiences of ethnic minority LGB individuals in Western countries (e.g. Crawford et al., 2002; Jaspal, 2014; Yip, 2007) clearly demonstrates some of the social psychological challenges individuals face in attempting to reconcile their sexual and ethnic/religious identities. However, there has been only minimal research into discrimination that ethnic minority gay men may also face from within the LGB community due to their ethnic minority identity. Their reported experiences on the "gay scene", ${ }^{1}$ that is, gay bars, pubs, clubs, and events, can enhance our understanding of this other source of discrimination. There has been only cursory research into the social and psychological aspects of ethnic/racial discrimination among LGB individuals (e.g. Choi et al., 2011; Diaz et al., 2001), and none that focuses specifically upon young British South Asian gay men (BSAGM). This article focuses upon perceived ethnic prejudice on the "gay scene" among young BSAGM - the largest ethnic minority group in the UK - and the impacts of this for their identities. Furthermore, drawing on Identity Process Theory from social psychology, the study examines how BSAGM may cope with potential threats to identity associated with perceived ethnic prejudice.

\section{Managing religious, ethnic and sexual identities}

Much research into the social psychological challenges of being LGB and of ethno-religious minority background shows that individuals face rejection from their ethno-religious community (Jaspal, 2014; Yip. 2007). Given that the ethno-religious community often constitutes an important and valued ingroup, perceived rejection from it may compromise one's psychological wellbeing (Phellas, 2005; Coyle and Rafalin, 2000; McKeown et al., 2010). This may be particularly acute for LGBT youths of ethnic minority background struggling to construct a positive sexual identity.

More recently, Jaspal and colleagues (Jaspal \& Cinnirella, 2012, 2014; Jaspal \& Siraj, 2011) have investigated the intersections of religion, ethnicity and sexuality among young BSAGM through the lens of Identity Process Theory (IPT) (Breakwell, 1986). The theory provides a social psychological framework for understanding the impacts of social and individual change for identity. The main premise of the theory is that when the individual is unable to construct an identity that is characterized by appropriate levels of (i) self-esteem, (ii) continuity, (iii) self-efficacy, (iv) distinctiveness, and (v) coherence, he/she faces identity threat, which can be aversive for psychological wellbeing. The threatened individual will attempt to cope with threat by engaging in intrapsychic, interpersonal and intergroup strategies.

BSAGM youth may face unique challenges in constructing and regulating identity. For many British South Asians, religious identity constitutes an important source of social and moral representations regarding sexuality. There is dominant perception among Muslims that only heterosexuality is compatible with Islam, the faith of most British Pakistanis (Murray, 1997). Similarly, ethno-cultural norms play a pivotal role in determining

\footnotetext{
${ }^{1}$ The gay scene http://www.bgiok.org.uk/being_gay/scene.html
} 
attitudes towards sexuality among Sikhs and Hindus, which are the most dominant religious affiliations of British Indians. One observable commonality between South Asians concerns their cultural prioritization of the concept of izzat (personal and cultural honor) (Ghuman, 2003). An essential tenet of maintaining familial izzat is the fulfillment of the cultural expectation of marriage, which in many cases is arranged by the family. Any contravention of cultural norms concerning sexuality (e.g. being gay) can be regarded as a threat to the family's honor, potentially resulting in negative consequences ranging from ostracization to psychological or physical abuse (Jaspal \& Siraj, 2011). This can lead to difficulties in establishing a common ingroup identity with others on the gay scene who may not share the same ethno-cultural norms and worldview (Gaertner \& Dovidio, 2000).

Young BSAGM may experience chronic threats to identity (Jaspal 2012). First, they may fail to establish feelings of compatibility and coherence between their ethno-religious and sexual identities which they see as being 'inter-connected'. This can be particularly acute when the ethno-religious ingroup is regarded as being opposed to homosexuality. Second, exposure to homophobia from one's ethno-religious community can have negative outcomes for self-esteem, since this may inhibit a positive self-conception on the basis of one's gay identity (Yip 2007). Third, individuals may fail to construct a psychological thread between past, present and future due to the perceived incongruence of their actual and desired "selves". In other words, the individual's self-construal as gay may be inconsistent with his desire to be heterosexual. Furthermore, given that South Asian ethnic cultures tend to attach importance to the institution of arranged marriage, many young BSAGM feel uncertain and fearful about their future (Jaspal, 2014). This research suggests that some BSAGM may cope with threatened identity (in relation to sexuality and ethnicity/religion) by denying their sexual identity - they may present themselves as "straight" and view their sexual behavior as a "phase". This may meet with disapproval from other gay men on the gay scene. Furthermore, some BSAGM manifest high levels of internalized homophobia and may themselves eschew close interpersonal relations with others on the gay scene, resulting in social isolation.

Although existing research has been useful in highlighting the psychological complexities of ethno-religious and sexual identification, it has focused largely upon the challenges of constructing a positive sexual identity among BSAGM amid perceived discrimination from their ethno-religious ingroup. There has been no systematic analysis of how another form of rejection - on the basis of one's ethnicity/religion - may impinge upon the construction of identity and how young BSAGM coming to terms with their sexuality may cope with it. This article explores the unique challenges that may be faced by BSAGM youth.

\section{Experiences of discrimination and racism}

There have been some media reports of racism on the (predominantly White) gay scene in Western countries, such as the US and the UK. A BBC news article (Buttoo, 2010) highlighted the fear that young BSAGM felt that racism would be directed towards them on the gay scene. The interviewees reported being refused service at bars or entry in clubs, as well as overt racism from White gay men (WGM), which led some individuals to avoid the gay scene. Moreover, there was a recent feature on racism on the gay scene in FS Magazine a gay men's health magazine, in which ethnic minority gay men provided testimonies concerning their experiences of racism and the impact it had on their wellbeing. ${ }^{2}$ Perceived racism on the gay scene might plausibly threaten identity among BSAGM - particularly, the

\footnotetext{
${ }^{2}$ Racism and the gay scene https://www.fsmag.org.uk/fs148-racism-and-the-gay-scene; What is it really like to be Black or Asian and gay? https://www.fsmag.org.uk/fs152-what-isit-really-like-to-be-black-or-asian-and-gay
} 
principle of self-esteem (Verkuyten, 1998). Some BSAGM may avoid frequenting spaces that could lead to identity-threatening experiences of racism.

In their qualitative research, Choi et al. (2011) found that US ethnic minority gay and bisexual men used deflection strategies to avoid the negative effects of homophobia and racism. In the US, Goode-Cross and Tager (2011) examined the experiences of young African American gay men who attended a predominantly White educational institution.

Participants reportedly perceived their racial identity to be more salient than their sexual identity in LGB contexts, which they believed impeded their access to LGB resources.

Similarly, BSAGM may feel "hyper-visible" on the basis of their ethnicity/ religion and, thus, feel unable to derive feelings of acceptance and inclusion in LGB spaces. They may anticipate and experience rejection on the basis of their minority identity.

In another study in the US, Battle et al. (2002) conducted a large survey of LGB African Americans, in which they found that half of the respondents perceived racism as a problem in their relations with White LGB individuals and that a third of respondents themselves reported negative intergroup experiences in predominantly White LGB organizations, bars and clubs. Additionally, two thirds of the respondents viewed homophobia as a problem in the African American community. Similarly, Brown (2008) has found that LGB African Americans generally feel that they are more likely to gain some acceptance and inclusion in predominantly White LGB settings when they "mute" or conceal their Blackness or when their Blackness is of sexual interest. It is unclear how BSAGM experience relations with ethnic/religious outgroup members on the gay scene and the strategies they employ to carve a space for themselves on it.

In their study of gay Arab and South Asian Muslim men in the US, Minwalla et al. (2005) observed that "race" played an important role in the social dynamics in White gay culture, which could result in feelings of exclusion among non-White men. However, there has been only cursory empirical insight into how BSAGM experience intergroup relations on the gay scene. Bhugra (1997) found that his gay Asian interviewees did not feel a complete sense of belonging in the gay community as a result of their ethnicity. Moreover, Bassi (2008) writes that "on the predominantly white commercial gay scene, gay and bisexual British Asians feel and carry the burden of racialization via the visible marker of their skin colour" (p.216-17).

In a qualitative interview study, Jaspal and Cinnirella (2012) found that some BSAGM frequented gay space to seek solace from their growing estrangement from their ethnic and religious identities. However, interpersonal relations on the gay scene could be complex - on the one hand, BSAGM initially preferred to associate with ethnic ingroup members due to the perception that the norms and constraints would be better understood by ingroup members but, on the other, a small number of respondents suggested that self-alignment alongside WGM enabled them to view their gay identity in a positive light. However, this research did not systematically examine the potential barriers that individuals might encounter in attempting to establish relationships with WGM on the gay scene.

The present study builds on this existing research by exploring perceptions of intergroup relations - primarily between BSAGM and WGM - in sexual identity contexts, and the impacts of these perceptions for identity through the lens of Identity Process Theory. There is a focus on how BSAGM construe and engage with the gay scene in view of the potential barriers to inclusion. Crucially, this study focuses on perception rather than experience, as some individuals may construe particular encounters as examples of prejudice due to previous experiences. 


\section{METHOD}

\section{Participants}

Using a snowball sampling strategy, 12 self-identified BSAGM were recruited in the West Midlands area. Seven participants were of Pakistani background and identified as Muslims, and the remaining 5 were of Indian background and identified as Sikhs. They all selfidentified as either "religious" or "moderately religious". Participants were aged between 18 and 25 years. Six participants had university-level qualifications, and the remaining 6 had completed college education. Four participants were in a monogamous relationship, 3 were in an "open relationship" and 5 were single. All of the participants reported having disclosed their sexual identity to small number of close friends but only 2 participants claimed to be "completely out".

\section{Procedure and analytic approach}

Interviews were guided by a semi-structured interview schedule consisting of 10 exploratory, open-ended questions. The schedule began with questions regarding selfdescription, self-categorization and identity, followed by more specific questions on the experiences on the gay scene, their friendships with other gay men, and perceptions and experiences of prejudice. Interviews lasted between 60 and 90 minutes. They were digitally recorded and transcribed verbatim.

The data were analyzed using thematic analysis which has been described as "a method for identifying, analyzing and reporting patters (themes) within data" (Braun \& Clarke, 2006, p. 78). When used in conjunction with Identity Process Theory, it can enable the analyst to capture participants' attempts to make sense of relevant aspects of their identities, focusing on the ways in which people discuss psychological constructs such as self-esteem, distinctiveness etc. In this study, thematic analysis was used to identify themes in the data that shed light on the meanings that lived experiences of intergroup relations on the gay scene hold for the individual, and how potential instances of identity threat may be managed at an individual level. A realist epistemological stance was taken in order to understand how participants themselves perceived the effects of the experiences for identity - their talk was thus considered a reflection of their cognitions.

The author transcribed the recordings and studied the transcripts. During each reading of the transcripts preliminary interpretations were noted in the left margin. These included inter alia participants' meaning-making, particular forms of language, and apparent contradictions and patterns within the data. Initial codes aimed to capture, from the analyst's perspective, participants' attempts to make sense of their identities and experiences. At the next step, the right margin was used to collate these initial codes into potential themes, which captured the essential qualities of the accounts. The list of themes was reviewed rigorously against the data in order to ensure their compatibility and numerous interview extracts were listed against each corresponding theme. At this stage specific interview extracts, which were considered vivid, compelling and representative of the themes, were selected for presentation in this article. Finally, three superordinate themes representing the analysis of participants' accounts were developed and ordered into a logical and coherent narrative structure. In the interview extracts presented in the next section, three dots indicate where material has been excised and other material within square brackets is for clarification.

\section{ANALYSIS}

In this section, the following three superordinate themes are outlined: (1) Ethnic otherization on the gay scene, (2) Mechanisms of rejection on the gay scene, and (3) Nowhere to turn: double rejection and identity threat. 


\section{Ethnic otherization on the gay scene}

For most interviewees, the gay scene had failed to live up to expectations. Far from viewing the gay scene as a safe space in which they could manifest their sexual identities, participants almost unanimously felt that they, and their ethno-cultural identities, were misunderstood by WGM:

I started going out with lots of expectations - I was like thinking I'll meet guys, chat, who knows, maybe find a boyfriend or something but it's pretty difficult for us, because White guys are pretty reserved around an Asian who comes along... They find it weird to see us there. (Hamid)

Individuals generally anticipated little acceptance of their sexual identity from their family circles and from ethnic ingroup members, which was conducive to identity threat and poor psychological wellbeing (McKeown et al., 2010). Consistent with social psychological theorizing around multiple group memberships (Ethier \& Deaux, 1994), some individuals attempted to derive feelings of acceptance and inclusion from a potential alternative group membership, namely the sexual ingroup. Hamid reportedly had "lots of expectations" about the benefits of frequenting the gay scene - he believed that he would be able to meet other gay men and possibly even a partner, thereby providing the means for enhancing his social and sexual capital (Yip, 2007). However, these expectations and aspirations were compromised by the reality that he encountered on the gay scene. Like other participants, he found it difficult to interact with WGM because of a perceptible intergroup "barrier". Hamid believed that they found the presence of South Asians on the gay scene anomalous, which had an impact on his own sense of belonging in this space. Mohammed too believed that he was otherized by WGM, which he attributed to their erroneous assumptions concerning Asians:

They have all these stereotypes about Asians, like "Oh, you're a Muslim so you must be all messed up", like "You are never gonna tell your parents that you're gay"... I hate all these damn baseless assumptions (Mohammed)

Like Mohammed, several interviewees believed that WGM held erroneous assumptions about Asian culture and, increasingly, about the Islamic faith. This was often attributed to growing Islamophobia in the UK (Allen, 2010). Mohammed perceived among WGM the stereotype that Muslims were "all messed up", that is, that they were socially and psychologically dysfunctional. He believed that the cultural distinctiveness of Asians was devalued and pathologized. However, the principal reason that most participants identified as underlying WGM's rejection of Asians concerned the issue of "coming out". On the whole, ethnic minority gay men tend to experience greater difficulties than WGM in disclosing their sexual identity to significant others (particularly within their ethnic ingroup) (Jaspal \& Siraj, 2011; Phellas, 2005). Given the positive cultural value that is appended to "coming out" in Western societies (Legate et al., 2012), the concealment of one's gay identity is often stigmatized and those who decide not to come out may be accused of identity inauthenticity or even betrayal of their sexual ingroup:

Just because I'm not out, it doesn't mean that I'm not gay... you just feel you've got to explain yourself (Karim)

Karim felt socially compelled to justify his decision not to disclose his gay identity publicly. Some interviewees believed that their refusal to come out was viewed unfavorably by WGM and that this cast doubt on their commitment to their gay identity. For Karim and others, 
this essentially illustrated a lack of understanding of the challenges they faced (McKeown et al., 2010). Participants perceived pressure from the ethno-religious ingroup to conceal their sexual identities, on the one hand, and a perception of pressure from the sexual ingroup to disclose their sexual identities, on the other. This was problematic for psychological coherence.

Individuals indicated that their inability to conform to key norms on the gay scene (such as "coming out" to one's family) rendered their identity vulnerable to contestation among WGM. As Hamid indicated, WGM may find the presence of BSAGM on the gay scene "weird" because they are viewed as being insecure about their sexual identity and, thus, as "outsiders". Mohammed was deeply offended by what he regarded as "baseless assumptions" about BSAGM. Awareness of these stereotypes appeared to challenge the distinctiveness principle of identity because they served to homogenize BSAGM :

I hate it because they are always thinking that I must be "like" something because I'm an Asian...I'm just thinking "maybe you should see me as a human with feelings and a personality"...that's what makes me different (Amir)

Respondents felt that WGM consistently attributed characteristics to them on the basis of their ethno-religious background, assuming that they "must be like something" because of their Asian-ness. Like Amir, several individuals indicated that they wished to be viewed primarily as individuals, but that their individual identities were obscured by group-level stereotypes (McKeown et al., 2010). Interviewees construed this as an intergroup barrier.

Similarly, Ravi regarded his ethno-religious background as excessively "dominating" conversations:

I have tried to fit in as much as I can but it always feel like something is in the way... You get into a conversation and all the questions are just about your race or then how is it that this happens in your culture or that happens? And I hate basing all the conversations on this. Once that's out the way, it's out the way and you've made no progress... I want to say "well, how about modern art, what's your view?" (Ravi)

Respondents lamented WGM's fixation on their ethnic identity which they felt inhibited discussions around other "normal" issues. This served to accentuate BSAGM's difference from others on the gay scene despite their desire to be viewed as (sexual) ingroup members. Their intergroup distinctiveness was accentuated vis-à-vis their shared sexual identity distinctiveness seemed to impede a sense of belonging (cf. Brewer, 1991).

Interviewees reportedly wished to demonstrate their various other group memberships:

I'm Asian. I'm Sikh. I'm British. But I'm also gay. But when I'm on the scene I'm still Asian but if as if everything else about me is not even seen. They don't seem to see that I'm gay...I'm just being seen as an Asian guy...I'm not considered one of them at all...I don't get that gay solidarity or gay pride crap that they go on about (Karan)

Several interviewees expressed dismay at the foregrounding of their ethnic identity in a social context in which their gay identity might plausibly be regarded as more contextually relevant. Like others, Karan believed that the foregrounding of his Asian ethnic identity obscured these other group memberships - most notably, his gay identity. This served only to exclude him from this social context and to impede access to the social capital associated with the gay scene. Asian and gay identities were reportedly not regarded as coherent given the visibility of his Asian ethnicity, Karan felt that the was not included as a sexual 
ingroup member. Consequently, gay affirmative, solidarity-raising events such as Gay Pride were simply not viewed as being available to him - Karan felt that he was less accepted and included in gay affirmative social contexts as a result of his ethno-religious background.

\section{Perceived mechanisms of rejection on the gay scene}

Interviewees reflected upon the various ways in which they were made to feel excluded from the gay scene:

They aren't many Asians on the scene - you know how it is, most of them aren't out and they are too scared to be seen out...You do get lonely on the scene because then there aren't many White people that are on your side (Amir)

BSAGM may feel uneasy about frequenting the gay scene due to the fear they may be identified by ethno-religious ingroup members (or even family members) or that their sexual identity may be disclosed by somebody on the gay scene. These fears can result in reluctance to socialize in these contexts. In absence of close interpersonal contacts on the gay scene, BSAGM who did decide to socialize in these contexts often reported a sense of solitude- they clearly did not perceive feelings of acceptance and inclusion from WGM and there were few ethno-religious ingroup members who could provide an alternative source of belonging.

Respondents struggled to articulate the nature of the discrimination that they perceived. Given that most participants attributed the lack of acceptance and inclusion to "race", there was a tendency to employ the term "racism" to capture how they felt:

I never faced racism until I came out, actually never. I never felt it at school or I never noticed it at least. I never felt it at work. But on the scene, yeah totally (Aman)

I do see it as racism, like when you try to get closer to a person and they automatically think "oh, shit, this Asian's hitting on me", "Asians are not my type" and then they back off (Mohammed)

Like Aman, several respondents had anticipated acceptance and inclusion on the gay scene but felt unable to establish friendships with WGM. A key reason outlined by Mohammed was that some mistook the advances of BSAGM as sexual, rather than platonic and amicable, which in turn impeded the establishment of friendship. Indeed, several interviewees invoked a stereotype that they are sexually unattractive to WGM. The "sexualization" of the gay scene reportedly allowed individuals to shun the (often non-sexual) advances of BSAGM under the pretext that "Asians are not my type".

Individuals acknowledged that, despite the prevalent culture of political correctness in most contexts, this did not apply to the gay scene in which racism was more explicitly manifested:

What really gets me is that lots of guys really rub it in your face and put stuff like "No Asians" [on their profiles]. Automatically, you're there thinking "I am not wanted by most guys on here, am I?" It's like your color they can't even see is already like out and you're not given a chance because of who you are...It's just like being Asian is a really bad thing in gay world and I'm ashamed of it sometimes (Raj)

Raj was referring to the gay social networking application Grindr, which he sometimes used to meet other gay men. Raj described the tendency for WGM to include a note on their profiles that they were not interested in BSAGM (Hasselriis, 2013). While some interviewees 
accepted that this might constitute a mere sexual preference, for most this implied that Asian-ness was an identity to be ashamed of and, thus, concealed. This could potentially threaten their sense of self-esteem on the basis of their ethnic identity (Verkuyten, 1998). Moreover, it became apparent to some individuals that this was not just a question of physical/ sexual preference - many WGM were reportedly unwilling to even converse with BSAGM. For Raj, such rejection on a social networking application constituted racism because he felt judged and unwanted primarily on the basis of his "race".

Similarly, some participants reported experiencing face-to-face rejection on the basis of their ethnicity, which constituted a distressing experience:

Just a little while back I just said hi to this guy and he goes "Not interested in Asians" and I just thought "Is this guy for real?" I felt really hurt and humiliated (Ali)

It's who I am. It's the color of my skin. My culture...It makes me realize that White people will never accept us and it kind of kills your confidence (Ahmed)

Participants came to view their ethnicity as a social "barrier" on the gay scene. Ali expressed disbelief and later pain and humiliation, as he was unaccustomed to such overt racism. Similarly, Ahmed felt that his self-confidence was compromised by perceived racism. These negative emotions ensued from the perception that one was being ostracized on the basis of an important and valued component of identity, namely their ethnicity. Rejection accentuated the perception of incompatibility between their sexual identity (dependent upon a sense of solidarity with other gay men) and their ethnic identity (which most people viewed as a visible marker). This could lead to threats to the psychological coherence principle of identity (Jaspal \& Cinnirella, 2012). For interviewees, the gay scene had become a prime context for experiencing discrimination on the basis of their ethnicity:

To me, it's the racism. They say all the stuff that's like suppressed in straight people...I just reckon that because they are gay, they think it's OK to say things even about Asians (Abdul)

Abdul regarded ethnic rejection as symptomatic of an underlying racism that had been "suppressed" among the White British majority due to the prevalent culture of political correctness but which could easily re-surface on the gay scene. Moreover, he suggested that gay people felt more able than heterosexual people to discriminate against ethnic minorities. Such experiences engendered the perception that the gay scene was not a "safe" or inclusive space for BSAGM. While in other non-gay contexts, homophobia constituted a possible threat due to invisible difference, in gay contexts racism was the more pressing and inescapable threat due to visible difference.

\section{Nowhere to turn: double rejection and identity threat}

The strong sense of rejection on the gay scene was particularly challenging because interviewees felt that they could not rely upon alternative sources of acceptance and inclusion:

White people never will accept us...Asians are too secretive so I don't hang out with them. Straight Asians think I'm just a queer so they are not really interested either. My parents? Don't even go there...I feel pretty trapped in my life (Abdul)

Abdul felt unable to establish enduring relationships with heterosexual British Asian men because of the homophobia that he anticipated. Indeed, several respondents indicated that, 
although they had not officially disclosed their sexual identity to others in their ethnic community, they were frequently subjected to homophobic name-calling and other forms of abuse. Conversely, some interviewees reportedly avoided befriending other BSAGM because they feared that this increased the risk of being "outed" to ethno-religious ingroup members. Research into the identities and experiences of BSAGM has demonstrated the fear that individuals have of disclosing their sexual identity to their parents and close family members due to the strong religious and cultural stigma surrounding homosexuality (Jaspal \& Siraj, 2011; Yip, 2007). Accordingly, respondents also felt that they could not confide in their families about their sexual identities and, thus, perceived a general lack of social support. Indeed, social support is pivotal for positive psychological functioning (Kessler et al., 1985).

While interviewees expressed trepidation about face-to-face encounters with other gay men, the online environment was originally perceived by many as a safer, more discreet space in which to explore and discuss their sexualities. However, echoing Raj's above-cited account, this environment was not conducive to a sense of belonging:

It's especially bad online...There are lots of idiots on Grindr, blatantly racist. I think Grindr is even more racist (Karim)

Previous research into social networking sites among gay men suggests that the Internet is an important context for relationship formation, since it provides a discreet space in which individuals can meet others with less fear of self-disclosure (Thomas et al., 2007). However, several interviewees regarded the online context as a poor context in which to form enduring relationships and to disclose aspects of the self in a safe manner. Many were afraid of making contact with WGM on Grindr because they anticipated negative, and sometimes racist, reactions from them:

I do think twice about sending a message on Grindr. It's never just a causal "hi". I'm thinking, "Will he be racist to me?" (Satpal)

Online contexts did not appear to offer individuals the same social psychological capital that has been described in previous research - like the gay scene, it was a context in which respondents struggled to derive a sense of belonging. This constituted a form of "double rejection" as individuals felt that they faced rejection in both online and offline contexts. Some respondents attempted to avoid rejection by concealing their ethnic background:

I know I should be proud of who I am....But sometimes I feel funny about telling people I'm Pakistani...you know the way people see Pakistani these days, well, it's not exactly good, is it? (Amir)

It's a bit like that lad from East is East that makes out he's White and then gets into a club, or the typical "I'm not Asian, I'm just tanned". I've done this a few times because I know what they'd be thinking if I say I'm Asian..."Mixed race" is better (Ravi)

I'm a Muslim but I don't tell anyone I'm a Muslim, anyone gay. I've had a few guys ask me what I am and I just say "atheist" or I'm sort of vague about it but I don't say it... just don't feel comfortable. Gay people are the last ones to accept a Muslim, for who I am...It's like leading another double life (Ali) 
Some interviewees felt ashamed of their ethnic background, indicating the resulting threat to self-esteem, and therefore sought to conceal it from public view. Amir's concealed his Pakistani ethnic identity because of the perceived stigma appended to it. Similarly, Ravi made reference to the British comedy East is East (Udwin \& O'Donnell, 1999), in which one of the main protagonists (a mixed heritage young man) successfully feigns membership in the White British majority in order to gain entry in a nightclub. Some respondents viewed their ethnic background as stigmatized because of the assumptions and stereotypes associated with the category. However, in some cases, they regarded it as a concealable stigma. The category "mixed race" evoked more positive connotations, for some of the interviewees. The notion of a mixed heritage background liberated Ravi from the (negative) stereotypes of traditionalism and conservatism that he perceived in relation to his Asian ethnicity. By passing as mixed heritage individuals, some individuals believed that they would more easily gain acceptance and inclusion from the White British majority (see Breakwell, 1986).

Like Amir and Ravi, Ali too employed the strategy of passing by feigning membership in the category "atheist", despite identifying as a Muslim. Interestingly, Ali and others in the study described their concealment of their ethno-religious identity and their inauthentic claim to other group memberships as "leading another double life". This of course referred to the perceived obligation to conceal their sexual identity from ethno-religious ingroup members, on the one hand, and to conceal their ethno-religious identity from sexual ingroup members, on the other. Although this facilitated feelings of acceptance and inclusion in the sexual ingroup, it was not conducive to identity authenticity, which could be challenging for the self-concept (Vannini \& Franzese, 2008).

\section{DISCUSSION}

Ethnic minority LGB individuals may experience difficulties in deriving social support from gay affirmative social contexts and in accessing LGB social resources, due to racism and exclusion (Choi et al., 2011; Diaz et al., 2001; Jaspal and Cinnirella, 2012). The present study demonstrates compellingly that BSAGM too may experience ethnic otherization in gay affirmative social contexts, in which they expect to be accepted and included, and the consequential feelings of rejection that they may come to associate with the sexual ingroup. In view of the existing otherization that they anticipate from the ethno-religious community, perceived rejection from gay affirmative social contexts and, more specifically, from WGM, may impede a positive sense of self. A key finding from this research is that young BSAGM may face multiple layers of rejection - racism and homophobia from several ingroups. This can pose multiple threats to identity and, thus, undermine social and psychological wellbeing among BSAGM.

\section{Perceived rejection and hostility from WGM}

Ethnic minority LGB individuals may struggle to reconcile their ethno-religious and sexual identities, due to a perception that the ethno-religious ingroup is fundamentally opposed to non-heterosexuality (Yip, 2007). Participants had attempted to assimilate and accommodate their sexualities within the self-concept by seeking gay affirmative social contexts and establishing interpersonal relations with sympathetic others. They viewed these contexts as key to the construction of a positive sexual identity. They expected, but did not receive, social support and solidarity from sexual ingroup members.

In contrast to previous research with BSAGM and Black British gay men (McKeown et al., 2010), the interviewees unanimously felt that the gay scene had not lived up to expectations, because of the rejection and, in some cases, hostility that they encountered. Racism posed a problem on the gay scene - individuals simply did not obtain a sense of 
acceptance and inclusion in a social context in which they wished to be viewed as ingroup, rather than outgroup, members. Prejudice could be attributed to the following factors:

- a general "sexualization" of gay space;

- a hyper-salience of ethnicity vis-à-vis sexual identity;

- the absence of "political correctness" on the gay scene.

Several respondents reported being shunned by WGM under the pretext that BSAGM were "not their type", despite the fact that many respondents reported seeking nothing more than friendship with them. There was a sense that, because the gay scene is "sexualized" ${ }^{3}$, this allowed WGM to view any advances from BSAGM through a sexual lens and, thus, to shun them on the basis of their ethnicity.

There was reportedly an accentuation of ethnic intergroup distinctiveness and an attenuation of their shared sexual identity (see Brewer, 1991). An overarching theme was that BSAGM's ethno-religious identity was consistently foregrounded in a social context in which they, conversely, wished to accentuate their shared sexual identity. The foregrounding of their ethnic identities in gay space was incongruent with social context and, thus, an impediment to a shared social identity.

Most interviewees discussed the culture of "political correctness" in contemporary Britain, which, despite its shortcomings, has protected ethnic minorities from overt discrimination (Fairclough, 2003). Yet, there was a widespread belief among interviewees that the culture of political correctness did not extend to the gay scene, in which it was reportedly easier for individuals to discriminate against BSAGM. More specifically, there was a perception among participants that, by virtue of their sexual minority identity and their own historical battle with homophobia (a form of prejudice), WGM believed that they possessed a "social license" to express their (sometimes racist) views in a candid manner.

\section{Identity, threat and coping}

Consistent with Identity Process Theory (Breakwell, 1986), the data suggest that ethnic otherization on the gay scene and the subtle mechanisms whereby BSAGM are made to feel that they do not belong in gay space can have negative outcomes for social psychological wellbeing. At a basic level, their presence on the gay scene may be viewed as anomalous, suggesting a need to creative more visibility for BSAGM on the gay scene. BSAGM may frequent gay space hoping that their sexual identity will be validated by others, but experience threats to identity when they encounter rejection instead. This can clearly sever the unifying psychological thread between past, present and future, imperiling their sense of continuity (Sani, 2008). Exposure to negative stereotypes concerning their ethno-religious identities, particularly in an era of increased Islamophobia, may induce a perception that this habitually valued group membership is tainted and shameful, potentially challenging the individual's sense of self-esteem - in short, it becomes difficult to derive a positive selfconception on the basis of one's ethno-religious identity (Gecas, 1982). This further illustrates the societal challenge of Islamophobia, which affects not only the general population but also BSAGM, many of whom already face other forms of prejudice and exclusion.

At a social level, BSAGM clearly feel that their affiliation, acceptance and inclusion in the ethnic and religious groups are susceptible to contestation because of their sexual minority background. For instance, previous research shows that some BSAGM of Muslim background question the authenticity of their Muslim identity due to their sexual orientation (Jaspal \& Cinnirella, 2014). Similarly, participants in this study also perceived their belonging in the sexual ingroup to be curtailed by ethnic prejudice that they encountered in gay space.

\footnotetext{
${ }^{3}$ The term "sexualization of gay space" refers to the perception among some individuals that the gay scene is primarily a context for seeking partners for sexual encounters.
} 
BSAGM may be made to feel "excessively" distinctive in a context in which they actually wish to belong, highlighting the tensions between distinctiveness and belonging. This tension has been articulated in Brewer's (1991) Optimal Distinctiveness Theory, which indicates that people strive to maintain an optimal balance of distinctiveness and belonging. Our respondents felt unable to achieve such a balance - BSAGM may face threats to identity as a result of the "double rejection" that they face.

In seeking to cope with threatened identity, some BSAGM may continue to use deflection strategies, such as denial or re-conceptualization of their gay identity, or a psychological "compartmentalization" of their ethno-religious and sexual identities (Breakwell, 1986). Some of the study participants sought solace in gay affirmative social contexts, in which they expected to meet other gay men. However, in these contexts individuals may experience difficulties in establishing close, high-quality interpersonal relations with WGM, due to differences in norms and expectations. There is a strong and coercive norm of "coming out" in Western societies, which may not be shared by BSAGM who face multiple challenges, such as pressure from friends and family to adhere to a heterosexual lifestyle. This can lead to accusations of identity inauthenticity, which can threaten identity.

Perceived ethnic prejudice can impede superordinate ingroup identification on the gay scene (Gaertner \& Dovidio, 2000), thereby curtailing important feelings of acceptance and inclusion (Baumeister \& Leary, 1995). In response to such threats to identity, BSAGM may engage in strategies for safeguarding a sense of belonging. Some respondents reported engaging in the strategy of passing by feigning membership in other ethnic/religious groups that they believed to be of greater social value. Given that they perceived negative social representations of both Asian and Islamic identities, individuals strategically embraced those ethnic identities that they believed would provide a sense of belonging. Ethnic identification is often correlated with a positive sense of self, and it can function as a social psychological buffer against the negative effects of racism (Brondolo et al., 2009; Mossakowski, 2003). Yet, the complexities associated with being gay and Asian may mean that individuals believe that they are not fully accepted by either of the two ingroups.

\section{Conclusions}

Complementing existing research into homophobia faced by BSAGM from within their ethno-religious communities, this study sheds lights on the potential impact of perceived ethnic prejudice on the gay scene. The data highlight the multiple sources of stigma and otherization that can pose "hyper-threats" to identity, that is, threats to multiple identity principles. While there has been some research into racism on gay scene faced by US ethnic minorities and, in particular, by African Americans, this study evidences the unique challenges faced by BSAGM. More specifically, increasing Islamophobia can severely impede a superordinate gay identity that can provide a safe space for BSAGM. Moreover, the cultural pressure to "come out" as gay in Western societies can further alienate BSAGM, many of whom face severe difficulties in disclosing their sexual identity to ethno-religious ingroup members.

This research highlights a clear need to create gay spaces in which BSAGM have greater visibility and are thus no longer viewed as anomalous and in which they can more readily acquire acceptance and inclusion. Interventions for challenging stereotypical (and particularly Islamophobic) views in gay spaces would be beneficial. Future interventions for prejudice reduction ought to acknowledge the three factors articulated in participants' accounts - sexualisation, hyper-salience of ethnicity and lack of political correctness. Identity Process Theory provides useful insights into the underpinnings of identity threat as experienced by BSAGM. It appears that the continuity, self-esteem and psychological coherence principles are most susceptible to threat. Therapeutic interventions that seek to 
enhance psychological wellbeing among BSAGM could target these principles of identity among this population. As illustrated in models of sexual minority identity construction (e.g. Cass, 1979), LGB individuals acquire "identity tolerance" as they begin to engage and meet with other LGB individuals. Ethnic prejudice on the gay scene may impede this process and deprive BSAGM of the only remaining source of social support that they perceive to be available. It is, thus, essential that gay affirmative social contexts remain accessible to the diverse social groups that identify as LGB.

\section{REFERENCES}

Allen, C. (2010). Islamophobia. Farnham: Ashgate.

Bassi, C. (2008). The precarious and contradictory moments of existence for an emergent British Asian gay culture. In C. Dwyer \& C. Bressey (Eds.), New geographies of race and racism (pp. 209-222). Farnham, UK: Ashgate.

Battle, J., Cohen, C.J., Warren, D., Fergerson, G. \& Audam, S. (2002). Say It Loud: I'm Black and I'm Proud; Black Pride Survey 2000. New York: The Policy Institute of the National Gay and Lesbian Task Force. www.ngltf.org Baumeister, R. F., \& Leary, M. R. (1995). The need to belong: Desire for interpersonal attachments as a fundamental human motivation. Psychological Bulletin, 117, 497-529. Bhugra, D. (1997). Coming out by South Asian gay men in the United Kingdom. Archives of Sexual Behaviour, 26(5), 547-557

Breakwell, G. M. (1986). Coping with threatened identities. London: Methuen.

Brewer, M.B. (1991). The social self: On being the same and different at the same time. Personality and Social Psychology Bulletin, 17, 475-482.

Brondolo, E., Brady ver Halen, N., Pencille, M., Beatty, D. \& Contrada, R.J. (2009). Coping with racism: a selective review of the literature and a theoretical and methodological critique. Journal of Behavioral Medicine, 32(1), 64-88.

Brown, C.E. (2008). Racism in the gay community and homophobia in the Black community: negotiating the gay black male experience. Unpublished M.Sc. in Sociology Dissertation. Virginia Polytechnic Institute and State University, Blacksburg, Virginia, USA.

Buttoo, S. (2010). Gay Asians reveal racism problems. BBC News, 8 March 2010. Available at: http://news.bbc.co.uk/1/hi/uk/8555503.stm

Cass, V. (1979). Homosexual identity formation: a theoretical model. Journal of Homosexuality, 4(3), 219-235.

Choi, K., Han, C., Paul J. \& Ayala, G. (2011). Strategies of Managing Racism and Homophobia among U.S. Ethnic and Racial Minority Men Who Have Sex with Men. AIDS Education and Prevention, 23(2), 145-158.

Coyle, A. \& Rafalin, D. (2000). Jewish gay men's accounts of negotiating cultural, religious and sexual identity: a qualitative study. Journal of Psychology and Human Sexuality, 12, 2148.

Crawford, I., Allison, K. W., Zamboni, B. D. \& Soto, T. (2002) The Influence of Dual-Identity Development on the Psychological Functioning of African-American Gay and Bisexual Men. The Journal of Sex Research, 39, 179-189.

Diaz, R., Ayala, G., Bein, E., Henne, J. \& Marin, B.V. (2001) The impact of homophobia, poverty, and racism on the mental health of gay and bisexual Latino men: findings from 3 US cities. American Journal of Public Health, 91, 927-932.

Ethier, K.A. \& Deaux, K. (1994). Negotiating social identity when contexts change: maintaining identification and responding to threat. Journal of Personality and Social Psychology, 67(2), 243-251.

Fairclough, N. (2003). 'Political correctness': the politics of culture and language. Discourse \& Society, 14(1), 17-28. 
Gaertner, S. L. \& Dovidio, J. F. (2000). Reducing intergroup bias: The common ingroup identity model. Philadelphia, PA: Psychology Press.

Gecas, V. (1982). The self-concept. Annual Review of Sociology, 8, 1-33.

Ghuman, P.A.S. (2003). Double loyalties: South Asian adolescents in the West. Cardiff, Wales: University of Wales Press.

Goode-Cross, D. T., \& Tager, D. (2011). Negotiating multiple identities: How African American gay and bisexual men persist at a predominately White institution. Journal of Homosexuality, 58, 1235-1254.

Hasselriis, K. (2013). Blocked on Grindr. Daily Xtra, 29 July 2013. Available at:

http://dailyxtra.com/toronto/ideas/features/blocked-grindr

Jaspal, R. (2014). Arranged marriage, identity and psychological wellbeing among British Asian gay men. Journal of GLBT Family Studies, 10(5), 425-448.

Jaspal, R. \& Breakwell, G.M. (eds.) (2014). Identity Process Theory: Identity, Social Action and Social Change. Cambridge: Cambridge University Press.

Jaspal, R. \& Cinnirella, M. (2012). Identity processes, threat and interpersonal

relations: accounts from British Muslim gay men. Journal of Homosexuality, 59(2), 215-40.

Jaspal, R. \& Cinnirella, M. (2014). Hyper-affiliation to the Religious Ingroup among British Pakistani Muslim Gay Men. Journal of Community and Applied Social Psychology, 24(4), 265277.

Jaspal, R. \& Siraj, A. (2011). Perceptions of 'coming out' among British Muslim gay men. Psychology and Sexuality, 2(3),183-197.

Kessler, R., Price, R., \& Wortman, C. (1985). Social factors in psychopathology: Stress, social support and coping processes. Annual Review of Psychology, 36, 531-572.

Legate, N., Ryan, R.M. \& Weinstein, N. (2012). Is Coming Out Always a "Good Thing"?

Exploring the Relations of Autonomy Support, Outness, and Wellness for Lesbian, Gay, and Bisexual Individuals. Social Psychological and Personality Science, 3(2), 145-152.

McKeown, E., Nelson, S., Anderson, J., Low, N. \& Elford, J. (2010). Disclosure, discrimination and desire: experiences of Black and South Asian gay men in Britain. Culture, Health and Sexuality, 12(7), pp. 843-856

Minwalla, O., Rosser, B. R. S., Feldman, J. \& Varga, C. (2005). Identity experience among progressive gay Muslims in North America: A qualitative study. Culture, Health and Sexuality, $7,113-128$.

Mossakowski, K.N. (2003). Coping with perceived discrimination: does ethnic identity protect mental health? Journal of Health and Social Behavior, 44(3), 318-31.

Murray, S.O (1997). The will not to know: Islamic accommodations of male homosexuality. In S.O. Murray \& W. Roscoe (eds.), Islamic homosexualities: Culture, history and literature (pp.14-54). New York, NY: New York University Press.

Phellas, C. N. (2005). Cypriot gay men's accounts of negotiating cultural and sexual identity: A qualitative study. Qualitative Sociology Review, 1(2), 65-83.

Sani, F. (Ed.) (2008). Self continuity: Individual and collective perspectives. Hove: Psychology Press.

Smith, J. A., \& Osborn, M. (2008). Interpretative phenomenological analysis. In J. A. Smith (Ed.), Qualitative psychology: A practical guide to methods (pp. 53-80). London, England: Sage.

Thomas, A.B., Ross, M.W. \& Harris, K.K. (2007). Coming out online: interpretations of young men's stories. Sexuality Research and Policy, 4(2), 5-17.

Trappolin, L., Gasparini, A. \& Wintemute, R. (2012). Confronting homophobia in Europe: social and legal perspectives. Oxford: Hart Publishing.

Udwin, L. (Producer) \& O'Donnell, D. (Director) (1999). East is East [Motion picture]. United Kingdom: Film4 Productions 
Vannini, P. \& Franzese, A. (2008). The authenticity of self: conceptualization, personal experience and practice. Sociology Compass, 2(5), 1621-37.

Verkuyten, M.J.A.M. (1998). Perceived discrimination and self-esteem among ethnic minority adolescents. Journal of Social Psychology, 138, 479-493.

Yip, A.K.T. (2007). Sexual orientation discrimination in religious communities. In M.V.L. Badgett \& J. Frank (Eds.), Sexual orientation discrimination: An international perspective (pp. 209-244). London, England: Routledge.

Yip, A.K.T. (2012). Homophobia and ethnic minority communities in the United Kingdom. In L. Trappolin, A. Gasparini \& R. Wintemute (eds.), Confronting homophobia in Europe: social and legal perspectives (pp.107-30). Oxford: Hart Publishing. 